\title{
Adiponectin deficiency impairs liver regeneration through attenuating STAT3 phosphorylation in mice
}

\author{
Run-Zhe Shu ${ }^{1,4,5}$, Feng Zhang ${ }^{1,4,5}$, Fang Wang ${ }^{2}$, De-Chun Feng ${ }^{1,4}, X_{\text {i-Hua Li }}^{2}$, Wei-Hua Ren ${ }^{2,3}$, Xiao-Lin Wu ${ }^{2}$, \\ Xue Yang ${ }^{2}$, Xiao-Dong Liao ${ }^{2}$, Lei Huang ${ }^{2}$ and Zhu-Gang Wang ${ }^{1,2,3}$
}

Liver regeneration is a very complex and well-orchestrated process associated with signaling cascades involving cytokines, growth factors, and metabolic pathways. Adiponectin is an adipocytokine secreted by mature adipocytes, and its receptors are widely distributed in many tissues, including the liver. Adiponectin has direct actions in the liver with prominent roles to improve hepatic insulin sensitivity, increase fatty acid oxidation, and decrease inflammation. To test the hypothesis that adiponectin is required for normal progress of liver regeneration, 2/3 partial hepatectomy $(\mathrm{PH})$ was performed on wild-type and adiponectin-null mice. Compared to wild-type mice, adiponectin-null mice displayed decreased liver mass regrowth, impeded hepatocyte proliferation, and increased hepatic lipid accumulation. Gene expression analysis revealed that adiponectin regulated the gene transcription related to lipid metabolism. Furthermore, the suppressed hepatocyte proliferation was accompanied with reduced signal transducer and activator of transcription protein 3 (STAT3) activity and enhanced suppressor of cytokine signaling 3 (Socs3) transcription. In conclusion, adiponectin-null mice exhibit impaired liver regeneration and increased hepatic steatosis. Increased expression of Socs 3 and subsequently reduced activation of STAT3 in adiponectin-null mice may contribute to the alteration of the liver regeneration capability and hepatic lipid metabolism after $\mathrm{PH}$.

Laboratory Investigation (2009) 89, 1043-1052; doi:10.1038/labinvest.2009.63; published online 29 June 2009

KEYWORDS: cell proliferation; hepatic steatosis; knockout mice; partial hepatectomy; Socs3; STAT3; PPAR $\alpha$

The liver has a central role in metabolic homeostasis, as it is responsible for the metabolism, synthesis, storage, and redistribution of nutrients, carbohydrates, fats, and vitamins. Paradoxically, it is also the main detoxifying organ of the body, which is frequently challenged by chemical, traumatic, or infectious injuries. Consequently, the liver has evolved a unique ability to regenerate in respond to liver mass loss because of injuries. ${ }^{1,2}$ Liver regeneration, which is driven by the replication of existing hepatocytes, is a process of compensatory hyperplasia rather than a differentiation process of stem cells. ${ }^{3}$

One of the most effective models for studying liver regeneration after hepatocellular loss is partial hepatectomy $(\mathrm{PH})$ in rodents. This technique, which was first described by Higgins and Anderson and performed in rats, ${ }^{4}$ can be modified to be safely and reproducibly performed in mice. ${ }^{5}$
After $\mathrm{PH}$, resection of about $2 / 3$ of liver mass results in quiescent hepatocytes rapidly re-entering the cell cycle. This highly regulated process is primed by different cytokines and growth factors that activate the downstream kinases and transcription factors. As a result, the hepatocytes initiate the transcription of more than 100 early genes, accumulate triglyceride and cholesterol to supply the energy and materials required for restore the liver mass. After one or two rounds of replication of hepatocytes, the original liver mass is restored within 5-7 days. Thus, liver regeneration constitutes a unique model to study signal transduction, lipid metabolism, and cell cycle events in a synchronized manner in vivo. ${ }^{2,3}$

Adipocytokines are soluble mediators mainly produced by adipocytes. They influence energy homeostasis and regulate neuroendocrine function as hormones; in addition, they affect immune functions and inflammatory processes as cyto-

\footnotetext{
'Key Laboratory of Stem Cell Biology, Institute of Health Sciences, Shanghai Institutes for Biological Sciences, Chinese Academy of Sciences, Shanghai Jiaotong University School of Medicine, Shanghai, China; ${ }^{2}$ Department of Medical Genetics, E-Institutes of Shanghai Universities, Shanghai Jiao Tong University School of Medicine, Shanghai, China; ${ }^{3}$ Shanghai Research Center for Model Organisms, Shanghai, China and ${ }^{4}$ Graduate School of Chinese Academy of Sciences, Shanghai, China Correspondence: Dr Z-G Wang, MD, PhD, Department of Medical Genetics, Shanghai Jiao Tong University School of Medicine, 280 South Chongqing Road, Shanghai 200025, China.

E-mail: zhugangw@shsmu.edu.cn

${ }^{5}$ These authors contributed equally to this work.

Received 16 January 2009; revised 18 April 2009; accepted 8 May 2009
} 
kines. Adiponectin (also known as APN, Acrp30, and GBP28) and leptin are the two most abundant adipocytokines produced by adipocytes. Adiponectin is decreased with obesity and is involved in many obesity-related metabolic disorders, such as insulin resistance, atherosclerosis, and fatty liver disease. ${ }^{6,7}$ Adiponectin interacts with at least two known cellular receptors (AdipoR1 and AdipoR2), which are both expressed in the liver. Binding of adiponectin to AdipoR1 and/or AdipoR2 stimulates the activation of peroxisome proliferator-activated receptor- $\alpha$ (PPAR $\alpha)$ and AMP-activated protein kinase (AMPK). ${ }^{8,9}$ Disruption of PPAR $\alpha$ mediated lipid signaling pathway delays the initiation of liver regeneration. ${ }^{10}$ Activation of AMPK stimulates $\beta$-oxidation to influence the lipid metabolism in hepatocytes. ${ }^{11}$ The first discovered adipocytokine, leptin, has been proved to be crucial during liver regeneration, ${ }^{12,13}$ but whether adiponectin is required during liver regeneration is still unknown. In addition, many evidences have proved that adiponectin has protective effects on many experimentally induced liver diseases. ${ }^{14-16}$ Taken together, we hypothesized that adiponectin plays a role in liver regeneration. To test this hypothesis, we studied the regeneration process triggered by $\mathrm{PH}$ in the liver of adiponectin knockout mice. Our results showed that adiponectin plays an essential role during liver regeneration.

\section{MATERIALS AND METHODS Animal Studies}

All the following studies were approved by the Animal Use and Care Committee of Shanghai Jiao Tong University School of Medicine. Adiponectin knockout and wild-type mice maintained in a $129 \mathrm{~S} 1$ background were kept on $12-\mathrm{h}$ dark-light cycles and maintained on standard mouse chow and water before and after surgery. ${ }^{17} \mathrm{PH}$ was performed on $8-12$-weeks-old male mice as described earlier. ${ }^{5}$ Briefly, animals $8-12$ weeks of age were anesthetized by pentobarbital. The three most anterior liver lobes (right upper, left upper, and left lower lobes), totaling about $68 \%$ of the liver, were tied at the origins of the lobes with three knots and then resected. The peritoneum was re-approximated with a running suture and then the skin was closed. Sterile saline $(1 \mathrm{ml})$ was administered subcutaneously on the back after closing the abdomen to replace fluid loss from the surgery. Mice were placed under warming lights for at least $1 \mathrm{~h}$ after surgery. All the surgeries were performed between 9:00 am and 12:00 pm by one person. At least four animals in each cohort were killed at each time point analyzed. For determination of total hepatocyte proliferation, BrdU (Sigma, St. Louis, MO, USA) was continuously given in drinking water to the mice after surgery. In another set of experiments, BrdU was injected intraperitoneally $1 \mathrm{~h}$ before killing as described earlier. ${ }^{18}$ At the time of killing, mice were anesthetized, and the remaining liver lobes were removed and weighed. For protein and RNA analysis, liver lobes were frozen in liquid nitrogen, and stored at $-80^{\circ} \mathrm{C}$ until use. For histological analysis, liver lobes were fixed in $10 \%$ formalin then embedded in paraffin, or soaked in $30 \%$ sucrose (in PBS) at $4^{\circ} \mathrm{C}$ overnight then frozen in OCT Compound (Sakura Finetek, Torrance, CA, USA).

\section{Cell Culture}

Human hepatoma, HepG2, cells were cultured in DMEM supplemented with 10\% FBS (Invitrogen, Carlsbad, CA, USA). HepG2 cells were serum starved overnight, then treated with or without recombinant human adiponectin (A kind gift from Dr Yan Chen, $10 \mu \mathrm{g} / \mathrm{ml}$ ) and leukemia inhibitory factor (LIF) (Chemicon, Temecula, CA, USA, $0.1 \mu \mathrm{g} /$ $\mathrm{ml}$ ) for $1 \mathrm{~h}$. Total RNA was isolated using the TRIzol reagent (Invitrogen).

\section{Liver Histology and Immunohistochemical Stainings}

Liver morphology was assessed based on 5- $\mu \mathrm{m}$ hematoxylin and eosin-stained paraffin sections. To assess the number of hepatocyte mitoses, 30 high-power microscope fields $(\times 400)$ from different liver sections for each sample were counted; counts were expressed as mitotic figures/10 highpower fields. Hepatocyte nuclear staining for BrdU was performed with primary BrdU antibody (sc-56258, SantaCruz Biotechnology, Santa Cruz, CA, USA) using the commercial kits (Santa-Cruz Biotechnology). Total BrdU-labeled hepatocytes were determined by counting positively stained hepatocyte nuclei in 10 high-power microscope fields $(\times 400)$ per liver. The cell proliferation index was calculated by dividing the number of labeled hepatocyte nuclei by the total number of hepatocyte nuclei counted, and the results were expressed as a percentage. Sections of liver frozen in OCT compound (Sakura Finetek) were stained with Oil Red O (Amresco, Solon, OH, USA) for analysis of hepatic fat accumulation.

\section{Liver Lipid Content}

Liver triglyceride and cholesterol were extracted as described earlier. ${ }^{19,20}$ Triglyceride and cholesterol levels were then measured using the Beckman-Coulter Synchron DxC800 chemistry analyzers (Fullerton, CA, USA) according to the manufacturer's instruction.

\section{Quantitative Real-Time Reverse Transcription PCR}

Differential gene expression was detected by quantitative realtime reverse transcription PCR. Total RNA was isolated from frozen liver tissue using the TRIzol reagent according to the manufacturer's protocol (Invitrogen). DNase I-treated (Promega, Madison, WI, USA) total liver RNA was reverse transcribed using AMV reverse transcriptase (Takara, Otsu, Japan). cDNA were reverse transcripted, respectively, and then the cDNA of the four mice with the same genotype in the same time point were mixed equally. PCR reaction mixes were assembled using the SYBR Green real-time PCR Master Mix (Toyobo, Osaka, Japan). The reactions were performed on the 7900HT Sequence Detection Quantitative PCR System (Applied Biosystems, Foster City, CA, USA). Cycling 
Table 1 Sequences of Primers for Quantitative Real-time RT-PCR

\begin{tabular}{lll}
\hline Genes & Forward & Reverse \\
\hline AdipoR1 & AATGGGGCTCCTTCTGGTAAC & GCAGACCTTATACACGAACTCC \\
AdipoR2 & GGAGTGTCGTGGGCTAGG & GCAGCTCCGGTGATATAGAGG \\
Fd36 & TCCTCTGACATTGCAGGTCTATC & AAAGGCATTGGCTGGAAGAA \\
Acc1 & GGAGGTGGTGATAGCCGGTAT & TGGGTAATCCATAGAGCCCAG \\
Cpt- 1 & ATGGGCGGATGGTCTCTTC & TGGGGACCTTGTCTCATCAT \\
PPAR $\alpha$ & AAAGATCAATCGGACCCTAGACA & CAGCGAGTAGCGCATAGTCA \\
$m$-Socs3 & GGGAAAGACCAGCAACAA & TCAAGGAGGACAGCATCG \\
$m$ - $\beta$ - actin & ATGGTCACCCACAGCAAGTTT & TCCAGTAGAATCCGCTCTCCT \\
$h$ - Socs3 3 - actin & CTGGCCGGGACCTGACAGACTACC & ATCGGAACCGCTCGTTGCCAATAG \\
& TGCGCCTCAAGACCTTCAG & GAGCTGTCGCGGATCAGAAA \\
\hline
\end{tabular}

parameters were $95^{\circ} \mathrm{C}$ for $3 \mathrm{~min}$ and then 40 cycles of $95^{\circ} \mathrm{C}$ $(25 \mathrm{~s}), 58^{\circ} \mathrm{C}(25 \mathrm{~s})$, and $72^{\circ} \mathrm{C}(25 \mathrm{~s})$ followed by a melting curve analysis. All reactions were performed with four technical replicates and repeated independently for three times. The cycle threshold values were normalized to the expression of the housekeeping gene $\beta$-actin. Primer sequences are available in Table 1.

\section{Western Blotting}

Frozen liver tissue was homogenized in RIPA buffer containing Protease Inhibitor Cocktail (Sigma) and PMSF with a homogenizer and a sonicator at $4^{\circ} \mathrm{C}$. After centrifuging at $10000 \mathrm{~g}$ for $10 \mathrm{~min}$ at $4^{\circ} \mathrm{C}$, the supernatant protein was quantified by the Bio-Rad DC Protein Assay (Hercules, CA, USA). Liver homogenates $(50 \mu \mathrm{g})$ were separated by SDSPAGE and were transferred to the nitrocellulose membrane as referred by the manufacturer's protocols. Antibodies of STAT3 (BD, Franklin Lakes, NJ, USA), phosphor-STAT3 (Tyr705) (Cell Signaling Technology, Danvers, MA, USA), and $\beta$-actin (Sigma) were used as probes. HRP-conjugated secondary antibodies were from Kirkegaard \& Perry Laboratories (Gaithersburg, MD, USA). Immune complexes were detected using the enhanced chemiluminescence system (Pierce, Rockford, IL, USA).

\section{Statistical Analysis}

Quantitative data are expressed as mean \pm s.d. Statistical significance between any two groups was determined by the two-tailed Student's $t$-test. $P$ values less than 0.05 were considered significant.

\section{RESULTS}

The Effect of Adiponectin Deficiency on Liver Mass Restoration and Hepatocyte Proliferation

To test the hypothesis that adiponectin is required for liver regeneration in vivo, we induced liver regeneration by performing $\mathrm{PH}$ on male wild-type and adiponectin-null mice. Mice were killed and analyzed during the first $96 \mathrm{~h}$ after surgery. Before $\mathrm{PH}$, there was no significant difference in the liver/body weight ratio between wild-type and adiponectinnull mice. However, the liver/body weight ratio was persistently lower in adiponectin-null mice from 24 to $96 \mathrm{~h}$ after $\mathrm{PH}$ (Figure 1a). During liver regeneration after $\mathrm{PH}$, the restore of liver mass is predominantly contributed by proliferation of the hepatocytes. To examine whether adiponectin deficiency causes an impairment of hepatocyte proliferation, wild-type and adiponectin-null mice were continuously labeled with BrdU and killed at 72 and $96 \mathrm{~h}$ after PH. Adiponectin-null mice showed significantly decreased proliferation than wild-type mice (Figure $1 \mathrm{~b}$ ). These results demonstrate that liver regeneration is impaired in adiponectin-null mice.

The peak of hepatocyte proliferation appears between 24 and $48 \mathrm{~h}$ after $\mathrm{PH}^{2,3}$ We assessed the kinetics of hepatocyte proliferation during liver regeneration in wild-type and adiponectin-null mice by evaluating hepatocyte DNA synthesis (BrdU pulse labeling) and counting mitotic hepatocytes after $\mathrm{PH}$. In wild-type mice, the proliferation index (percentage of BrdU-positive hepatocytes) markedly increased at $36 \mathrm{~h}$ post $\mathrm{PH}$, reached a peak at $48 \mathrm{~h}$ post $\mathrm{PH}$, then decreased to a low level at $72 \mathrm{~h}$ post $\mathrm{PH}$. Nevertheless, in adiponectin-null mice, the proliferation index was persistently lower from 36 to $60 \mathrm{~h}$ post $\mathrm{PH}$ and a little higher at $72 \mathrm{~h}$ post $\mathrm{PH}$ (Figure $1 \mathrm{c}$ and $\mathrm{d}$ ). The mitotic figures of hepatocytes were counted and we found that much more mitotic figures were observed at 48 and $60 \mathrm{~h}$ post $\mathrm{PH}$ in the liver of wild-type mice in comparison with the adiponectin-null mice (Figure le and f). HE staining of liver tissue sections also revealed that both of the wild-type and adiponectin-null livers had increased vacuolation after PH. However, the vacuolation level, which may represent the hepatic steatosis (lipid accumulation), in adiponectin-null mice was obviously higher than that in the 

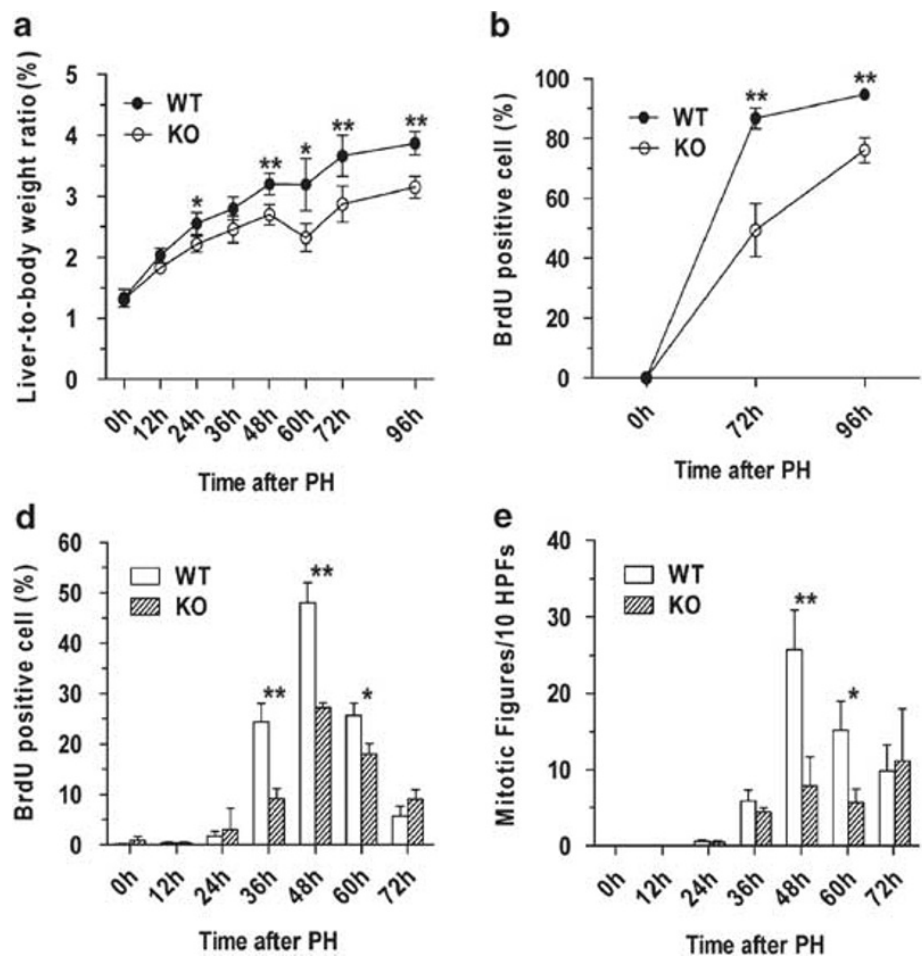

c
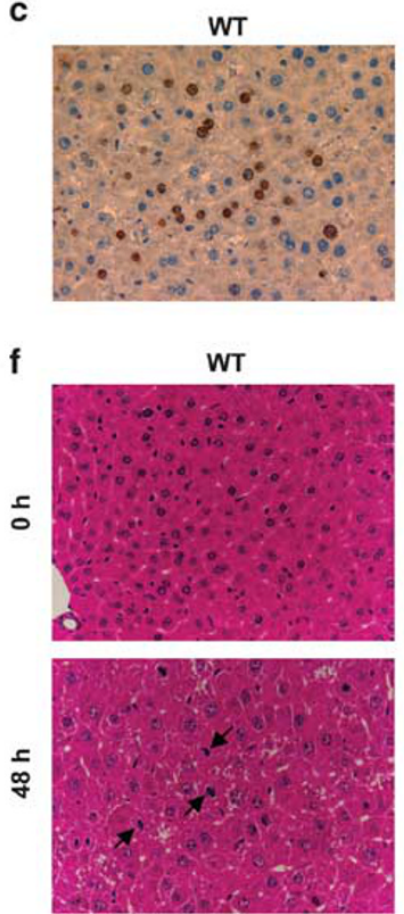
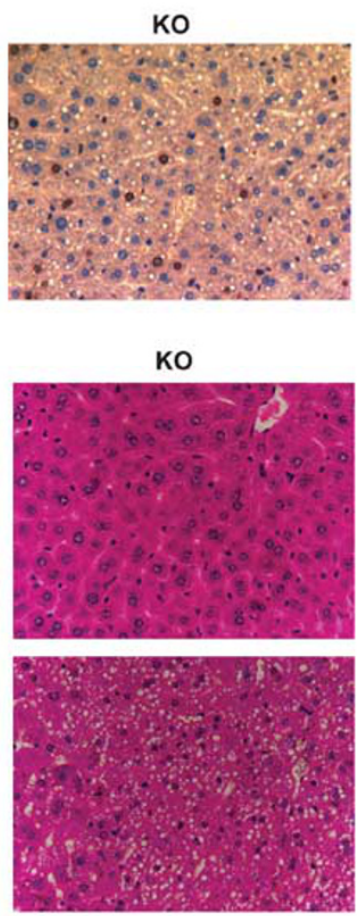

Figure 1 Impaired restoration of liver mass and hepatocyte proliferation in adiponectin-null mice. (a) Liver/body weight ratio in wild-type (WT) and adiponectin-null (KO) mice at the indicated time points after $\mathrm{PH}$. (b) Cumulative proliferation of hepatocytes after PH. Mice were given BrdU in drinking water until the time of killing. (c) 1-h BrdU pulse labeling of hepatocytes in livers from wild-type (WT) and adiponectin-null (KO) mice at $48 \mathrm{~h}$ after $\mathrm{PH}$ (magnification, $\times 400$ ). (d) Percentage of BrdU-positive hepatocyte nuclei in all nuclei in wild-type (WT) and adiponectin-null (KO) mice at the indicated time points after PH. (e) Counts of mitotic figures in wild-type and adiponectin-null mice at the indicated time points after PH. (f) Morphologic assessment of livers from wild-type and adiponectin-null mice at 0 and $48 \mathrm{~h}$ after $\mathrm{PH}$. The representative photomicrographs of hematoxylin and eosin-stained paraffin sections of the liver are shown (magnification, $\times 400$ ). The arrows denote the representative mitotic figures. Results are shown as mean \pm s.d. ( $n \geq 4$ for each genotype at each time point). ${ }^{\star} P<0.05,{ }^{*} P<0.01$.

wild-type mice at $48 \mathrm{~h}$ post $\mathrm{PH}$. Hepatic steatosis and focal liver injury were more prominent in the adiponectin-null mice (Figure 1f). We also evaluated the apoptosis level in the livers of both wild- type and adiponectin-null mice at $48 \mathrm{~h}$ post $\mathrm{PH}$ using the TUNEL staining, but no significant difference was found (data not shown). Taken together, these results clearly show that the hepatocyte proliferation of adiponectin-null mice is impeded during the regeneration after $\mathrm{PH}$.

\section{The Effect of Adiponectin Deficiency on Hepatic Lipid Accumulation and Catabolism During Liver Regeneration}

After $\mathrm{PH}$, transient hepatic steatosis occurs during early liver regeneration. Mice exhibit markedly increased hepatic lipid accumulation at $12-24 \mathrm{~h}$ after $\mathrm{PH}$. And the hepatic lipid was consumed away $24-48 \mathrm{~h}$ after $\mathrm{PH}$, which was proposed to serve as an energy and materials source supporting cell proliferation and tissue re-growth. ${ }^{13}$ However, It is well established that excessive lipid accumulation in liver exhibits profound impairment of liver regeneration after $\mathrm{PH} .{ }^{12,21-25}$ Adiponectin functions as a hormone to stimulate lipid catabolism. ${ }^{26}$ It reduces lipid accumulation by inhibiting hepatic lipogenesis and stimulating fatty acid oxidation. ${ }^{14,27}$ These reports led us to determine whether adiponectin has effect on hepatocellular lipid accumulation and catabolism during liver regeneration. The timing and magnitude of hepatic steatosis during liver regeneration after $\mathrm{PH}$ were examined by Oil Red O staining. Compared to wild-type mice, much more fat accumulated in adiponectin-null livers at $24 \mathrm{~h}$ post $\mathrm{PH}$ (Figure 2a). Moreover, at $48 \mathrm{~h}$ post $\mathrm{PH}$, though the hepatocellular lipid decreased to a low level in wild-type livers, the lipid in adiponectin-null livers was still abundant (Figure 2a). Corresponding biochemical data supported the morphological observation (Figure $2 \mathrm{~b}$ and $\mathrm{c}$ ). Increased hepatic triglyceride and cholesterol accumulation were determined in adiponectin-null mice, whereas the levels of triglyceride and cholesterol in serum were not significantly different between wild-type and adiponectin-null mice before $\mathrm{PH}$ and after $\mathrm{PH}$ (Supplementary Figure 1). These results demonstrate that adiponectin plays an essential role in regulating hepatic lipid homeostasis during liver regeneration.

\section{Expression of Genes Involved in Lipid Metabolism during Liver Regeneration}

In an attempt to explore the molecular mechanism underlying adiponectin-mediated hepatic lipid metabolism during 

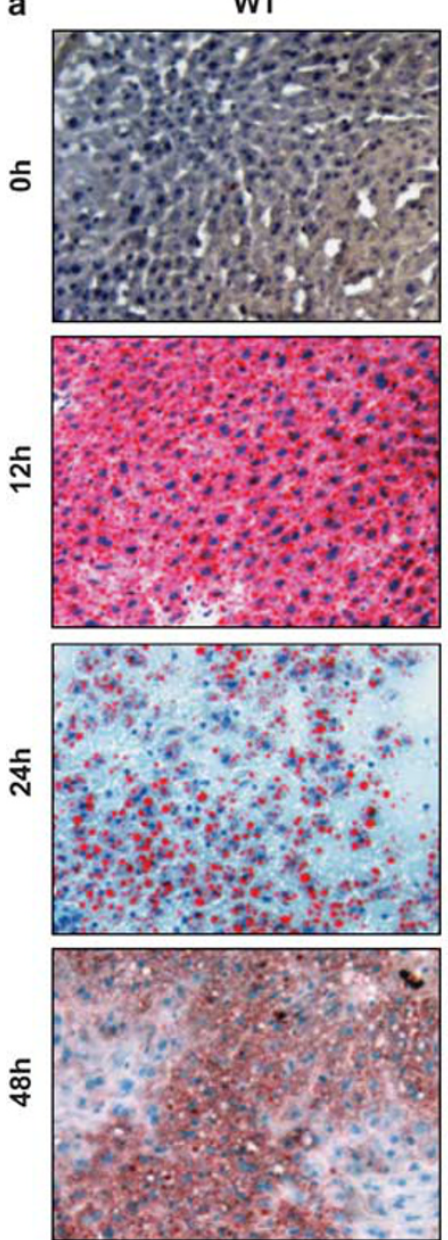
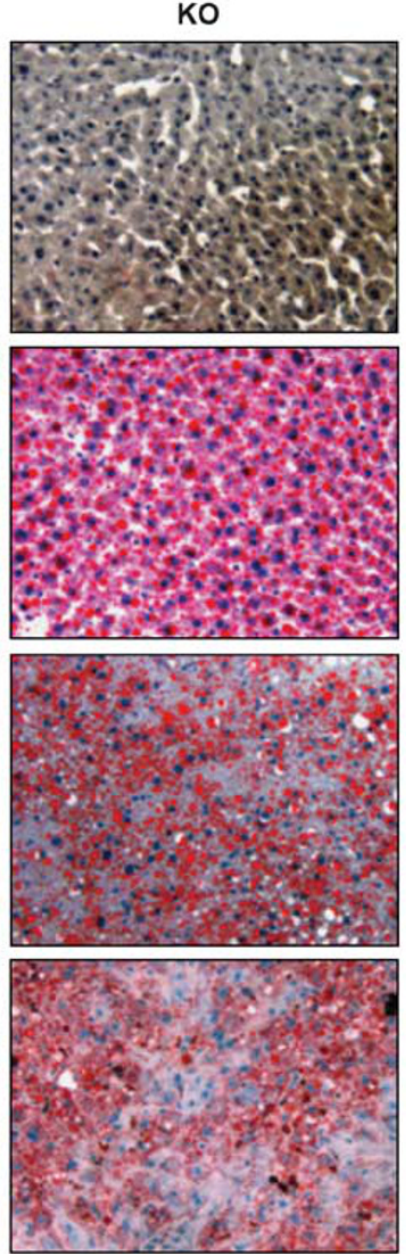

b
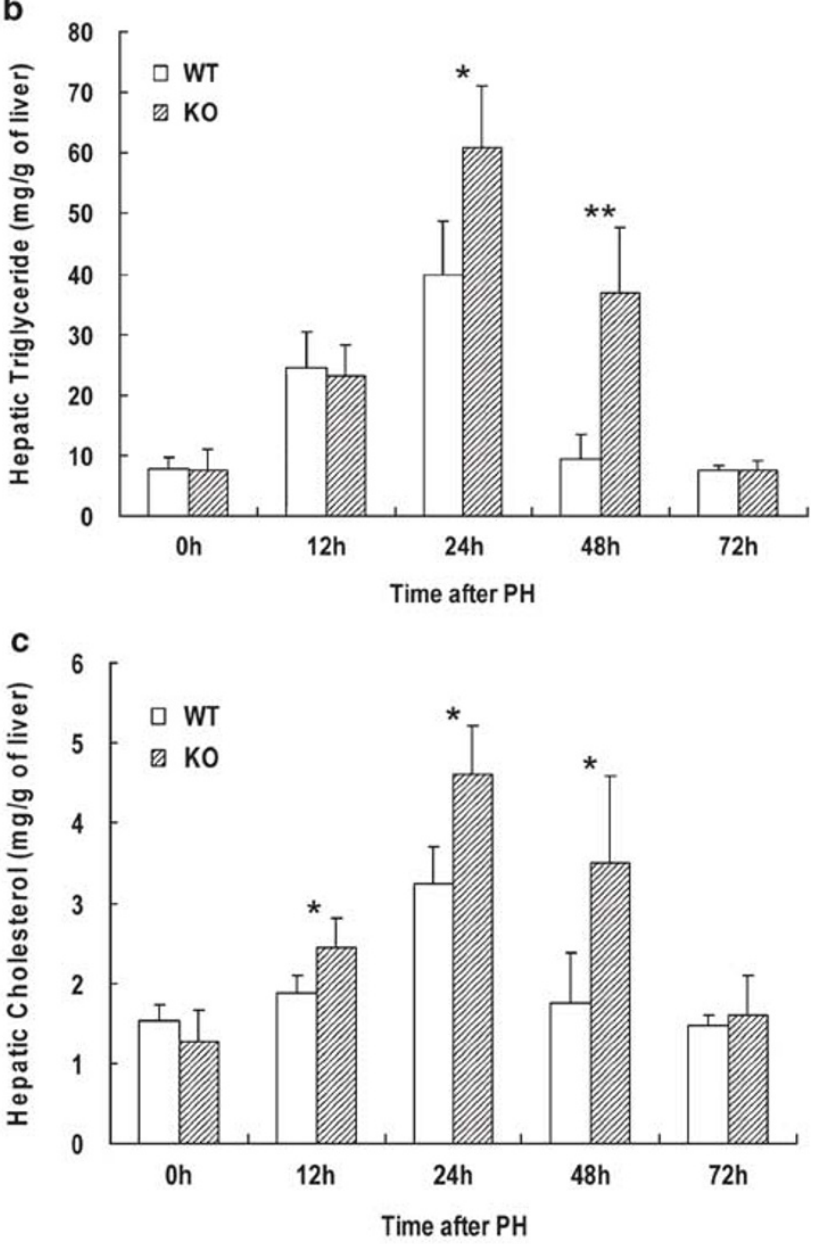

Figure 2 Increased hepatic lipid accumulation in adiponectin-null mice after PH. (a) Oil Red O staining of livers from wild-type (WT) and adiponectin-null (KO) mice at the indicated time points after $\mathrm{PH}$ (magnification, $\times 200$ ). Hepatic triglyceride (b) and cholesterol $(\mathbf{c})$ levels were measured using the livers collected at the indicated time points after PH. Results are shown as mean \pm s.d. ( $n \geq 4$ for each genotype at each time point). ${ }^{\star} P<0.05,{ }^{\star} P<0.01$.

liver regeneration, expression of genes known to be critical in lipogenesis, fatty acid oxidation, and transportation was profiled by relative quantitative real-time reverse transcription PCR. We found that the mRNA levels of carnitine palmitoyltransferases I (Cpt-I), PPAR $\alpha$, acetyl-CoA-carboxylase 1 (Acc1), fatty acid synthase (Fas), and Cd36 were changed in the absence of adiponectin in comparison with wild-type mice during liver regeneration. The average hepatic mRNA level of each gene in wild-type livers at $0 \mathrm{~h}$ was set as 1.0, and the hepatic mRNA level of each gene at $24 \mathrm{~h}$ after sham operation was set as a control.

Cpt-I is a rate-limiting enzyme involved in the transport of long-chain fatty acids into mitochondrial matrix. ${ }^{28}$ It has been well demonstrated that adiponectin can increase the activity of Cpt-I to enhance fatty acid oxidation. ${ }^{14}$ Our data showed that, at 0,12 , and $24 \mathrm{~h}$ after $\mathrm{PH}$, the hepatic Cpt-I mRNA level was higher in wild-type mice than that in adiponectin-null mice. At $48 \mathrm{~h}$ post $\mathrm{PH}$, the hepatic Cpt-I mRNA level in adiponectin-null mice was equal to the level in wild-type mice. At $72 \mathrm{~h}$ post $\mathrm{PH}$, the hepatic Cpt-I mRNA level in adiponectin-null mice was about 1.7-fold higher than that in wild-type mice (Figure 3a). These findings show that, the upregulation of Cpt-I mRNA is delayed in adiponectinnull mice.

$\operatorname{PPAR} \alpha$, which can be activated by adiponectin, is a critical regulator of hepatic lipid oxidation. ${ }^{29}$ The hepatic PPAR $\alpha$ mRNA level was higher in wild-type mice at 24 and $48 \mathrm{~h}$ after $\mathrm{PH}$ but a little lower at $72 \mathrm{~h}$ after $\mathrm{PH}$ as compared to that in adiponectin-null mice (Figure $3 \mathrm{~b}$ ). Obviously, the upregulation of PPAR $\alpha$ mRNA expression, which is similar to that of the Cpt-I mRNA expression, is delayed in adiponectin-null mice.

Fas is another key enzyme involved in hepatic lipogenesis. Expression of hepatic Fas is significantly elevated after PH, and adiponectin can suppress the hepatic mRNA expression of this enzyme. ${ }^{14,28}$ From 12 to $48 \mathrm{~h}$ after $\mathrm{PH}$, the hepatic Fas mRNA level was consistently higher in adiponectin-null mice compared to wild-type mice. At $48 \mathrm{~h}$ post $\mathrm{PH}$, the level of 

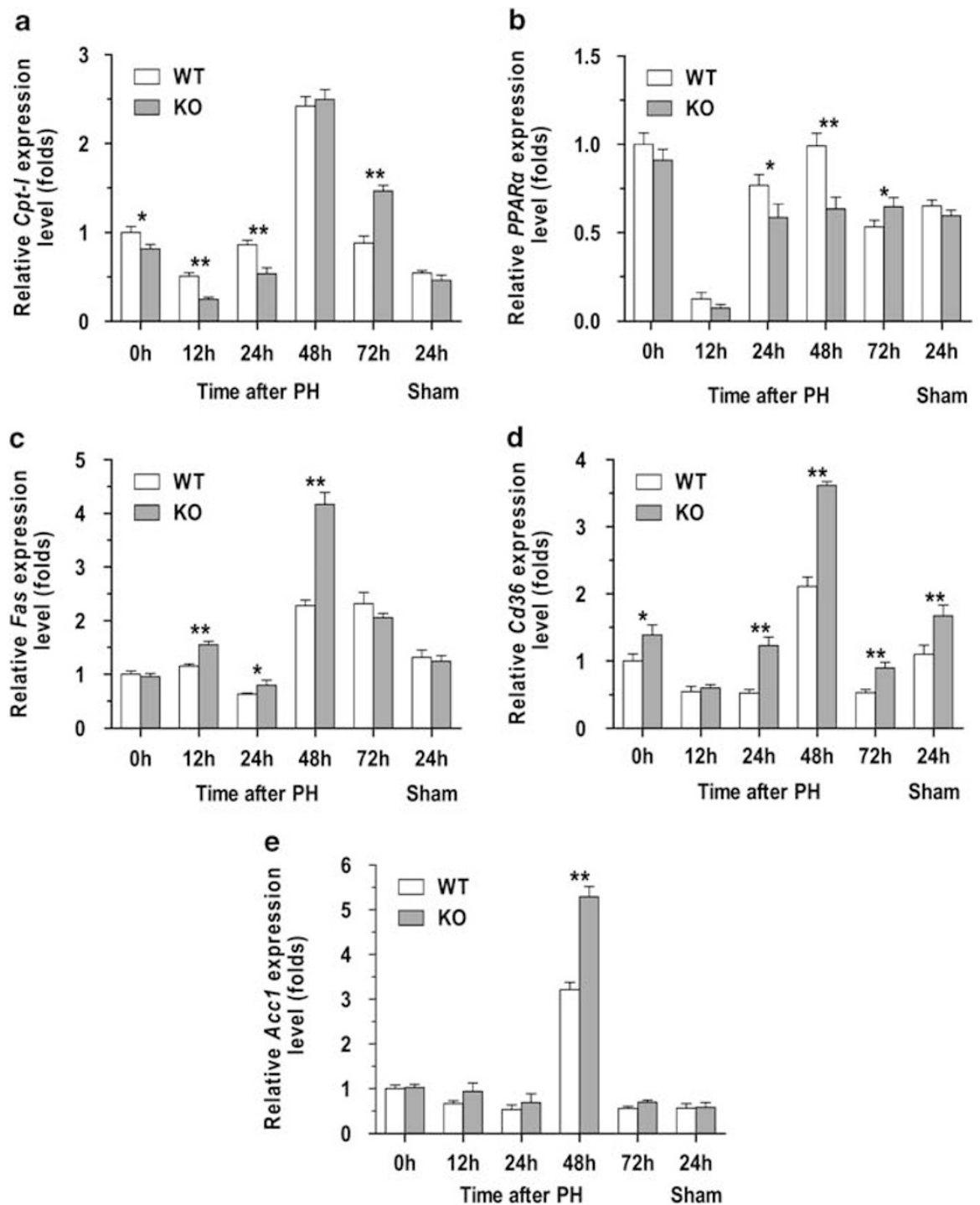

Figure 3 Expression of genes involved in lipid metabolism during liver regeneration. The hepatic mRNA levels of Cpt-I (a), PPAR $\alpha$ (b), Fas (c), Cd36 (d) and Acc1 (e) of wild-type (WT) and adiponectin-null (KO) mice at the indicated time points after PH or sham operation (Sham) were measured by quantitative real-time reverse transcription PCR. Data are shown as mean of fold changes compared with wild-type mice $0 \mathrm{~h}$ after surgery \pm s.d. $(n=3)$. ${ }^{\star} P<0.05$, $* * P<0.01$.

hepatic Fas transcripts was about 2-fold higher in adiponectin-null mice than that in wild-type mice (Figure 3c). These data demonstrate that adiponectin can suppress the Fas expression to regulate the hepatic lipogenesis during liver regeneration after $\mathrm{PH}$.

$\mathrm{Cd} 36$ is a protein responsible for transportation of fatty acids into tissues, ${ }^{30}$ and adiponectin treatment can markedly downregulate the hepatic expression of Cd36. ${ }^{14}$ Both before $\mathrm{PH}$ and at $24 \mathrm{~h}$ after sham operation, adiponectin-null livers expressed higher Cd36 mRNA level than wild-type livers. This observation suggests that adiponectin might control the basal PPAR $\alpha$ mRNA level. At 24,48 , and $72 \mathrm{~h}$ post $\mathrm{PH}$, adiponectin-null livers consistently expressed at about 2-fold higher Cd36 mRNA than wild-type livers (Figure 3d). These data suggest that $\mathrm{PH}$-induced $\mathrm{Cd} 36$ gene expression might be modulated by adiponectin.
Acc1 is a lipogenic enzyme known to be suppressed by adiponectin. ${ }^{9,14}$ Marked induction of Accl gene expression was seen in both wild-type and adiponectin-null livers at $48 \mathrm{~h}$ post PH. However, the level of hepatic Accl transcript was 1.6-fold higher in adiponectin-null mice than that in wildtype mice at this time point (Figure 3e). These data indicate that adiponectin is involved in the regulation of Accl gene expression during liver regeneration.

\section{The Adiponectin Protein Levels and mRNA Expression of Adipors during Liver Regeneration}

To investigate the function status of adiponectin during the process of liver regeneration, we detected the adiponectin protein level and the expression pattern of adiponectin receptors (AdipoRs). As expected, there were high levels of adiponectin protein in livers of wild-type mice but no 
a

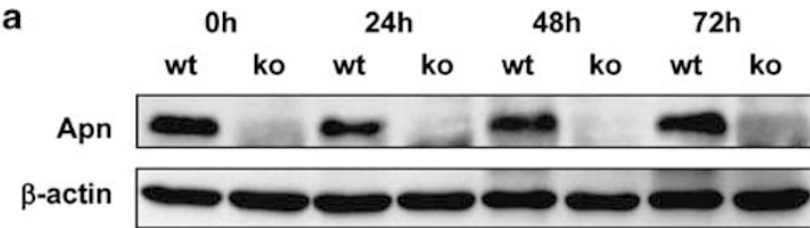

b

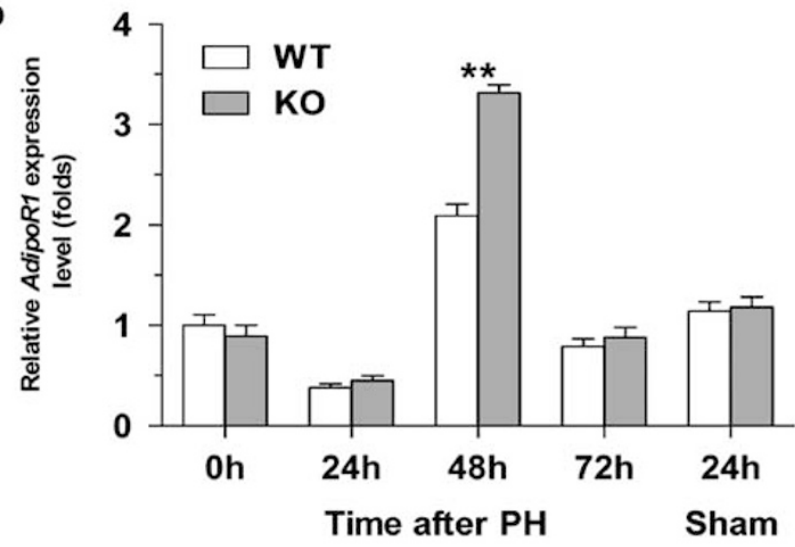

C

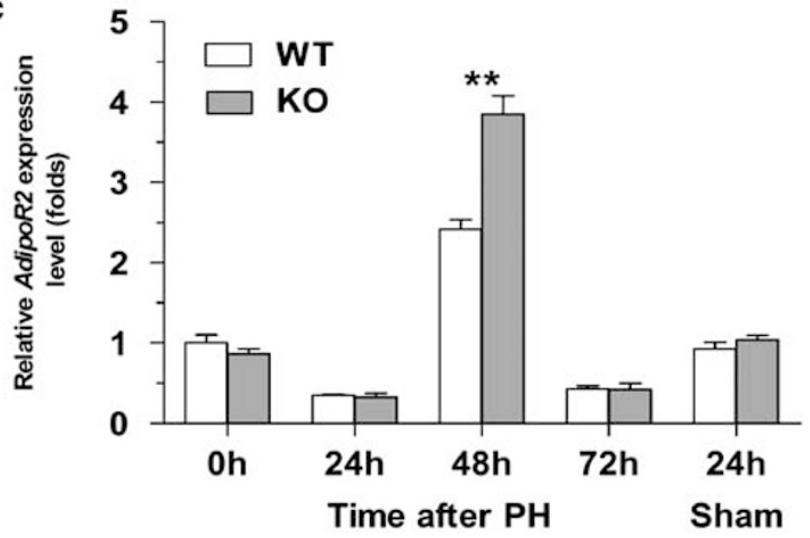

Figure 4 The hepatic protein levels of adiponectin and mRNA levels of AdipoRs during liver regeneration. (a) Immunoblotting of adiponectin in liver homogenates corresponding to wild-type (wt) and adiponectin-null (ko) mice after PH. Immunoblots are representative of three independent experiments. The hepatic mRNA levels of two adiponectin receptors AdipoR1 (b) and AdipoR2 (c) in wild-type (WT) and adiponectin-null (KO) mice at the indicated time points after PH were measured by quantitative real-time reverse transcription PCR. Data are shown as mean of fold changes compared with wild-type mice $0 \mathrm{~h}$ after surgery \pm s.d. $(n=3)$. $* * P<0.01$.

adiponectin protein was detected in livers of adiponectin-null mice at any point in the regeneration process (Figure 4a). Two receptors for adiponectin (AdipoR1 and AdipoR2) have been identified. AdipoR1 is expressed widely in mice, whereas AdipoR2 is expressed mainly in the liver. ${ }^{8,9}$ Interestingly, the hepatic mRNA levels of AdipoR1 and AdipoR2 both increased after $\mathrm{PH}$ and reached a peak at $48 \mathrm{~h}$ post $\mathrm{PH}$. Moreover, in the absence of adiponectin, the mRNA levels of AdipoR1 and AdipoR2 were higher than those of wild-type mice at $48 \mathrm{~h}$ post $\mathrm{PH}$ (Figure $4 \mathrm{~b}$ ).

\section{Reduced Hepatic STAT3 Activity in Adiponectin-Null Mice after $\mathrm{PH}$}

Cytokine signaling pathways are activated after $\mathrm{PH}$. The interleukin-6 (IL-6)-induced JAK-STAT3 pathway is a key cytokine signaling during liver regeneration. Binding of IL- 6 to its receptor (IL-6R), which is associated with two subunits of gp130, stimulates the tyrosine-kinase activity of the Janusassociated kinase (JAK). Activated JAK then phosphorylates the associated gp130 and STAT3 on a tyrosine residue. STAT3 then homodimerizes and translocates to the nucleus, where it induces transcription of a number of target genes to promote the liver regeneration. ${ }^{2,3}$ Suppressor of cytokine signaling 3 (Socs3) interacts with JAK and blocks JAK-STAT3 pathway to suppress the process of liver regeneration. ${ }^{31,32}$ To evaluate whether absence of adiponectin affects STAT3-mediated signaling during liver regeneration, hepatic functional status of STAT3 was analyzed by western blotting. From 24 to $72 \mathrm{~h}$ after $\mathrm{PH}$, the phosphorylation of STAT3 was obviously reduced in adiponectin-null mice (Figure 5a). Meanwhile, at 24 and $48 \mathrm{~h}$ post $\mathrm{PH}$, the Socs 3 mRNA levels in the adiponectinnull mice were about 2-fold higher than those in the wildtype mice (Figure 5b). To determine whether Socs 3 mRNA levels can be regulated by adiponectin, human hepatoma, HepG2, cells were treated with human recombinant adiponectin (APN). After APN treatment, the Socs3 mRNA level was reduced by $32.5 \%$ in HepG 2 cells. The gene expression of Socs 3 was acutely induced by LIF treatment, ${ }^{33}$ and this induction was reduced by $24.7 \%$ on the addition of APN (Figure 5c). These findings suggest that adiponectin can repress the Socs 3 gene transcription. For this reason, the reduced STAT3 activation in adiponectin-null mice after $\mathrm{PH}$ is partially resulted from the increased Socs 3 level.

\section{DISCUSSION}

In this study, we have investigated the role of adiponectin in liver regeneration after $\mathrm{PH}$. Our results show that adiponectin is required for normal procession of liver regeneration.

In clinical situations, obese patients with fatty livers tend to have poor outcomes after resection or liver transplantation. $^{21-23}$ In experimental situations, both genetic-based models and high-fat-diet-induced model proved that preexisting steatosis caused significant impairment of liver regeneration after $\mathrm{PH}^{12,24,25}$ In addition, the augmented hepatic steatosis after $\mathrm{PH}$ coexisted with the defective liver regeneration after $\mathrm{PH}$ in mice. ${ }^{10,34}$ This phenomenon was observed in adiponectin-null mice as well. These evidences suggest that excessive fat in hepatocytes may harm the normal process of liver regeneration. In the normal progress of liver regeneration after $\mathrm{PH}$, hepatic lipid homeostasis is complex and exactly regulated..$^{13}$ In the absence of adiponectin, hepatocytes accumulated much more lipid, and the lipid could not be consumed away efficiently. Meanwhile, mRNA levels of related lipid metabolism genes consistently changed. In the early phase after PH, mRNA levels of Cpt-I and $\operatorname{PPAR} \alpha$ had increased higher in wild-type mice in 

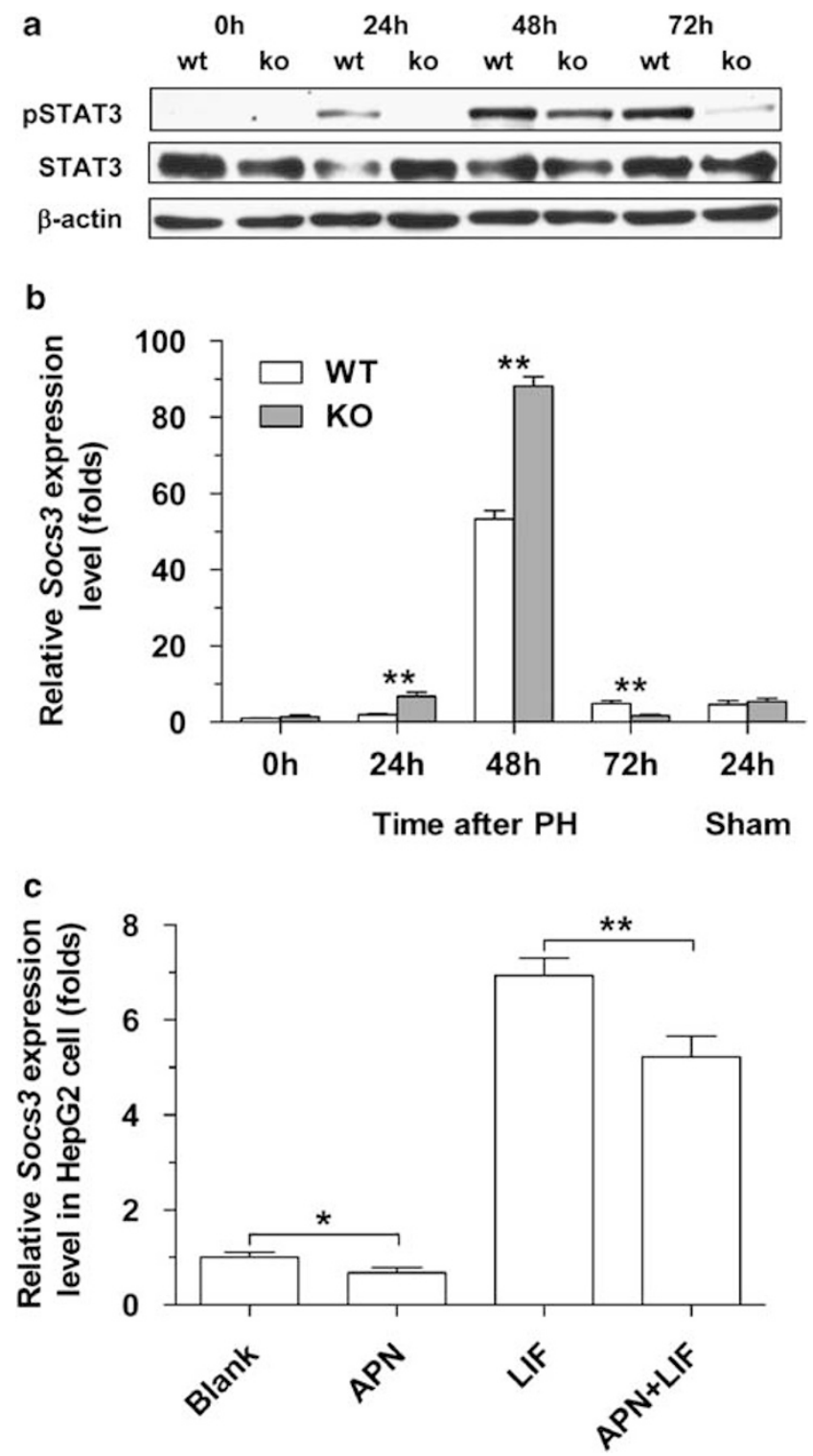

Figure 5 Decreased STAT3 phosphorylation and increased Socs3 mRNA levels after PH in adiponectin-null mice. (a) Total and phosphorylated STAT3 were assessed by western blot in the livers of wild-type (WT) and adiponectin-null (KO) mice at the indicated time points after $\mathrm{PH}$. $\beta$-actin is included as a loading control. (b) The hepatic mRNA levels of Socs3 of wildtype (WT) and adiponectin-null (KO) mice at the indicated time points after $\mathrm{PH}$ were measured by quantitative real-time reverse transcription PCR. Data are shown as mean of fold changes compared with wild-type mice $0 \mathrm{~h}$ after surgery \pm s.d. $(n=3)$. (c) Serum-starved HepG2 cells were treated with or without recombinant human adiponectin (APN) and LIF for $1 \mathrm{~h}$. Relative levels of Socs3 mRNA were determined by quantitative real-time reverse transcription PCR. Results are shown as average of three independent experiments \pm s.d. ${ }^{\star} P<0.05,{ }^{* *} P<0.01$.

comparison with adiponectin-null mice. These adiponectindependent changes of gene expression might lead to enhanced lipid $\beta$-oxidation. Though the mRNA levels of Cpt-I and PPAR $\alpha$ increased to normal levels and even higher levels later, the lipid $\beta$-oxidation might be late for the requirement of energy in the adiponectin-null mice. Moreover, wild-type mice have reduced mRNA levels of Fas, Cd36, and Acc1. These adiponectin-dependent changes of gene expression might suppress the lipid biosynthesis and uptake to modulate the hepatic lipid homeostasis during the liver regeneration. Taken as a whole, these results suggest that adiponectin-null mice could not catabolize the accumulated hepatocellular lipid efficiently to fuel the fire for the normal progress of liver regeneration.

The reduced STAT3 activity and increased Socs 3 mRNA level could also contribute to the augmented hepatic steatosis in the adiponectin-null mice. The liver-specific STAT3 deficiency mice show reduced hepatocyte DNA synthesis after $\mathrm{PH}$ were complicated with obesity and fatty liver. ${ }^{35,36}$ In addition, inhibition of the expression of Socs3 in liver ameliorates hepatic steatosis, and Socs 3 enhances the hepatic steatosis by attenuating STAT3 activity. ${ }^{37}$ Earlier study has shown that IL-6 treatment alleviates hepatic steatosis through enhancing STAT3 activation as well as upregulating PPAR $\alpha$ expression and activity in mice. ${ }^{38}$ Recently, it has been reported that fructose-fed rats show impairment of hepatic STAT-3 activation as well as reduction in PPAR $\alpha$ mRNA expression and activity. ${ }^{39}$ In our study, adiponectin-null mice also showed reduced STAT3 activity and PPAR $\alpha$ mRNA expression during the early phase of liver regeneration. These results suggest that STAT3 and PPAR $\alpha$ may take part to the regulation of the hepatic lipid accumulation during liver regeneration. However, the detail mechanisms on the cross talk between these two pathways remain to be demonstrated.

Recent studies suggest that adiponectin can activate STAT3 in the rat hypothalamus and mouse cardiac fibroblasts. ${ }^{40,41}$ Our results provide in vivo evidence that adiponectin can stimulate the STAT3 activation in mouse livers after PH, which is accompanied by reduced Socs 3 transcription. Moreover, our results provide in vitro evidence that adiponectin can repress Socs 3 transcription. However, we found no significant difference in serum levels and hepatic expression levels of IL-6 between wild-type and adiponectin-null mice (data not shown), which indicate that the decreased STAT3 phosphorylation during liver regeneration represents a direct effect of the adiponectin-dependent Socs3 induction. This is, to our knowledge, the first report to demonstrate that adiponectin-mediated repression of Socs3 gene expression can facilitate STAT3 activation. The direct involvement of the adiponectin-AdipoRs signaling in the induction of Socs 3 expression and reduction in STAT3 phosphorylation still requires further investigations.

This study also provides evidence that the transcription of AdipoRs is enhanced after PH. Moreover, the mRNA levels of AdipoRs compensatorily increased in adiponectin-null mice at $48 \mathrm{~h}$ post $\mathrm{PH}$. These results suggest that the downstream signaling cascades of AdipoRs triggered by adiponectin are required in the normal progression of liver regeneration. However, one of the principal downstream signal transduction proteins, AMPK phosphorylation, did not significantly change during liver regeneration in both wild-type and adiponectin-null mice (data not shown). 


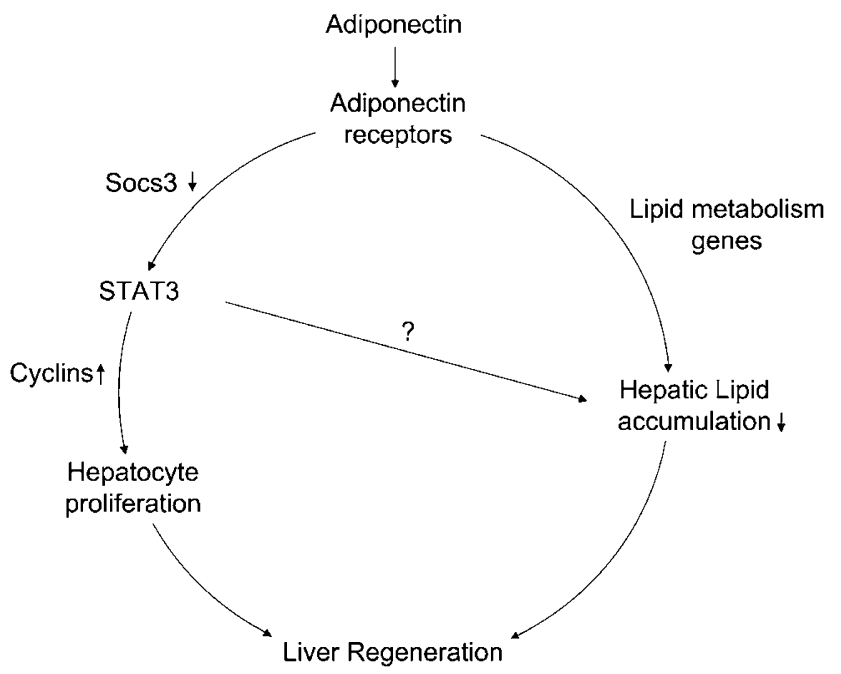

Figure 6 Schematic representation of the potential mechanisms underlies the actions of adiponectin during liver regeneration.

When we were preparing our manuscript, Hisao Ezaki and colleagues published their work about the effects of adiponectin on liver regeneration after $\mathrm{PH}$ using different mice strain. ${ }^{42}$ Our study was generally in agreement with their report on the role of adiponectin during liver regeneration after $\mathrm{PH}$. By $\mathrm{PH}$ in C57BL/6 mice, they found that delayed liver regeneration was due to reduced expression of cyclins and impairment of fatty acid oxidation. Our investigation on the 129S1 mice indicated that adiponectin-null mice showed impaired liver regeneration and abnormal fatty acid metabolism. Moreover, our results described the reduced phosphorylation of STAT3 and increased transcription of Socs3 in adiponectin-null mice after $\mathrm{PH}$. It has been proved that activation of STAT3 after PH can promote hepatocyte proliferation through enhancing expression of cyclins. ${ }^{36}$ These evidences collectively showed the potential mechanisms underlie the actions of adiponectin during liver regeneration (Figure 6).

In summary, adiponectin-null mice showed impaired liver regeneration and altered hepatic lipid accumulation after PH. Increased Socs 3 and subsequently blocked STAT3 signaling in adiponectin-null mice may contribute to the alteration of the liver regeneration capability and hepatic lipid metabolism after $\mathrm{PH}$. Taken together, these results suggest that adiponectin and AdipoRs could be the novel targets to improve liver regeneration in patients with acute or chronic liver injury.

Supplementary Information accompanies the paper on the Laboratory Investigation website (http://www.laboratoryinvestigation.org)

\section{ACKNOWLEDGEMENTS}

We thank Dr Jian Guan from Sixth People's Hospital of Shanghai Jiaotong University and Ying Wang from Institute of Health Sciences for technical assistance in partial hepatechtomy; Dr Yan Chen from Institute of Nutritional Sciences for providing recombinant human adiponectin protein; Dr Yi-Shi Fan from Clinical laboratory of Ruijin Hospital of Shanghai Jiaotong University for assistance in triglyceride and cholesterol levels measurement.
This work is partially supported by the grants from the National Natural Science Foundation of China (30470951, 39925023, 30530390), the Ministry of Science and Technology of China (2006BAI23B02), the Ministry of Education of China (00TPJS111), and by grants from the Science and Technology Commission of Shanghai Municipality (07DZ22929, 06DZ05907), and E-Institutes of Shanghai Municipal Education Commission (E03003).

\section{DISCLOSURE/CONFLICT OF INTEREST}

The authors declare no conflict of interest.

1. Michalopoulos GK, DeFrances MC. Liver regeneration. Science 1997;276:60-66.

2. Taub R. Liver regeneration: from myth to mechanism. Nat Rev Mol Cell Biol 2004;5:836-847.

3. Fausto N, Campbell JS, Riehle KJ. Liver regeneration. Hepatology 2006;43:S45-S53.

4. Higgins GM, Anderson RM. Experimental pathology of the liver. I. Restoration of the liver of the white rat following partial surgical removal. Arch Pathol 1931;12:186-202.

5. Greene AK, Puder M. Partial hepatectomy in the mouse: technique and perioperative management. J Invest Surg 2003;16:99-102.

6. Arita $\mathrm{Y}$, Kihara $\mathrm{S}$, Ouchi $\mathrm{N}$, et al. Paradoxical decrease of an adiposespecific protein, adiponectin, in obesity. Biochem Biophys Res Commun 1999;257:79-83.

7. Hu E, Liang P, Spiegelman BM. AdipoQ is a novel adipose-specific gene dysregulated in obesity. J Biol Chem 1996;271:10697-10703.

8. Tilg H, Moschen AR. Adipocytokines: mediators linking adipose tissue, inflammation and immunity. Nat Rev Immunol 2006;6:772-783.

9. Yamauchi T, Kamon J, Ito Y, et al. Cloning of adiponectin receptors that mediate antidiabetic metabolic effects. Nature 2003;423:762-769.

10. Anderson SP, Yoon L, Richard EB, et al. Delayed liver regeneration in peroxisome proliferator-activated receptor-alpha-null mice. Hepatology 2002;36:544-554.

11. Yamauchi T, Kamon J, Minokoshi Y, et al. Adiponectin stimulates glucose utilization and fatty-acid oxidation by activating AMPactivated protein kinase. Nat Med 2002;8:1288-1295.

12. Yang SQ, Lin HZ, Mandal AK, et al. Disrupted signaling and inhibited regeneration in obese mice with fatty livers: implications for nonalcoholic fatty liver disease pathophysiology. Hepatology 2001;34:694-706.

13. Shteyer E, Liao Y, Muglia $L$, et al. Disruption of hepatic adipogenesis is associated with impaired liver regeneration in mice. Hepatology 2004;40:1322-1332.

14. Xu A, Wang $\mathrm{Y}$, Keshaw $\mathrm{H}$, et al. The fat-derived hormone adiponectin alleviates alcoholic and nonalcoholic fatty liver diseases in mice. J Clin Invest 2003;112:91-100.

15. Kamada $Y$, Tamura S, Kiso S, et al. Enhanced carbon tetrachlorideinduced liver fibrosis in mice lacking adiponectin. Gastroenterology 2003;125:1796-1807.

16. Masaki T, Chiba S, Tatsukawa $\mathrm{H}$, et al. Adiponectin protects LPSinduced liver injury through modulation of TNF-alpha in KK-Ay obese mice. Hepatology 2004;40:177-184.

17. Ren W, LI X, Wang F, et al. Generation of adiponectin gene knock-out and lacZ gene knock-in mouse model. Prog Biochem Biophys 2006;33:846-853.

18. Columbano A, Ledda-Columbano GM, Pibiri M, et al. Gadd45beta is induced through a CAR-dependent, TNF-independent pathway in murine liver hyperplasia. Hepatology 2005;42:1118-1126.

19. Zhou J, Zhai $Y, M u ~ Y$, et al. A novel pregnane $X$ receptor-mediated and sterol regulatory element-binding protein-independent lipogenic pathway. J Biol Chem 2006;281:15013-15020.

20. Ferramosca A, Savy V, Conte L, et al. Conjugated linoleic acid and hepatic lipogenesis in mouse: role of the mitochondrial citrate carrier. J Lipid Res 2006;47:1994-2003.

21. Todo S, Demetris AJ, Makowka L, et al. Primary nonfunction of hepatic allografts with preexisting fatty infiltration. Transplantation 1989;47:903-905.

22. D'Alessandro AM, Kalayoglu M, Sollinger HW, et al. The predictive value of donor liver biopsies for the development of primary nonfunction after orthotopic liver transplantation. Transplantation 1991;51:157-163. 
23. Behrns KE, Tsiotos GG, DeSouza NF, et al. Hepatic steatosis as a potential risk factor for major hepatic resection. J Gastrointest Surg 1998;2:292-298.

24. Yamauchi $\mathrm{H}$, Uetsuka $\mathrm{K}$, Okada $\mathrm{T}$, et al. Impaired liver regeneration after partial hepatectomy in $\mathrm{db} / \mathrm{db}$ mice. Exp Toxicol Pathol 2003;54:281-286.

25. DeAngelis RA, Markiewski MM, Taub R, et al. A high-fat diet impairs liver regeneration in $\mathrm{C} 57 \mathrm{BL} / 6$ mice through overexpression of the NF-kappaB inhibitor, IkappaBalpha. Hepatology 2005;42:1 148-1157.

26. Ahima RS. Metabolic actions of adipocyte hormones: focus on adiponectin. Obesity (Silver Spring) 2006;14(Suppl 1):9S-15S.

27. Shklyaev S, Aslanidi G, Tennant M, et al. Sustained peripheral expression of transgene adiponectin offsets the development of diet-induced obesity in rats. Proc Natl Acad Sci USA 2003;100:14217-14222.

28. Asins G, Rosa JL, Serra D, et al. Gene expression of enzymes regulating ketogenesis and fatty acid metabolism in regenerating rat liver. Biochem J 1994;299(Pt 1):65-69.

29. Berger J, Moller DE. The mechanisms of action of PPARs. Annu Rev Med 2002;53:409-435.

30. Bonen A, Campbell SE, Benton CR, et al. Regulation of fatty acid transport by fatty acid translocase/CD36. Proc Nutr Soc 2004;63:245249.

31. Riehle KJ, Campbell JS, McMahan RS, et al. Regulation of liver regeneration and hepatocarcinogenesis by suppressor of cytokine signaling 3. J Exp Med 2008;205:91-103.

32. Seki $E$, Kondo $Y$, limuro $Y$, et al. Demonstration of cooperative contribution of MET- and EGFR-mediated STAT3 phosphorylation to liver regeneration by exogenous suppressor of cytokine signalings. J Hepatol 2008;48:237-245.
33. Auernhammer CJ, Bousquet C, Melmed S. Autoregulation of pituitary corticotroph SOCS-3 expression: characterization of the murine SOCS-3 promoter. Proc Natl Acad Sci USA 1999;96:6964-6969.

34. Beyer TA, Xu W, Teupser D, et al. Impaired liver regeneration in Nrf2 knockout mice: role of ROS-mediated insulin/IGF-1 resistance. EMBO J 2008;27:212-223.

35. Inoue $\mathrm{H}$, Ogawa W, Ozaki $\mathrm{M}$, et al. Role of STAT-3 in regulation of hepatic gluconeogenic genes and carbohydrate metabolism in vivo. Nat Med 2004;10:168-174.

36. Li W, Liang X, Kellendonk C, et al. STAT3 contributes to the mitogenic response of hepatocytes during liver regeneration. J Biol Chem 2002;277:28411-28417.

37. Ueki K, Kondo T, Tseng YH, et al. Central role of suppressors of cytokine signaling proteins in hepatic steatosis, insulin resistance, and the metabolic syndrome in the mouse. Proc Natl Acad Sci USA 2004;101:10422-10427.

38. Hong F, Radaeva S, Pan HN, et al. Interleukin 6 alleviates hepatic steatosis and ischemia/reperfusion injury in mice with fatty liver disease. Hepatology 2004;40:933-941.

39. Roglans N, Vila L, Farre M, et al. Impairment of hepatic Stat-3 activation and reduction of PPARalpha activity in fructose-fed rats. Hepatology 2007;45:778-788.

40. Coope A, Milanski M, Araujo EP, et al. AdipoR1 mediates the anorexigenic and insulin/leptin-like actions of adiponectin in the hypothalamus. FEBS Lett 2008;582:1471-1476.

41. Liao W, Yu C, Wen J, et al. Adiponectin induces interleukin-6 production and activates STAT3 in adult mouse cardiac fibroblasts. Biol Cell 2009;101:263-272.

42. Ezaki H, Yoshida $Y$, Saji $Y$, et al. Delayed liver regeneration after partial hepatectomy in adiponectin knockout mice. Biochem Biophys Res Commun 2009;378:68-72. 